\title{
8
}
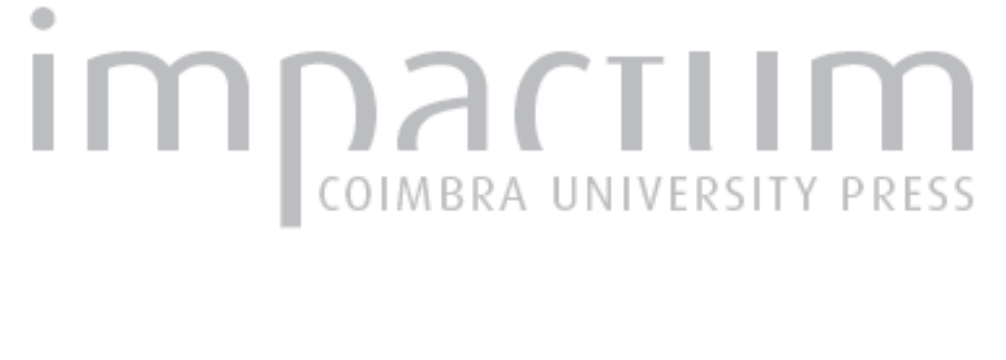

\section{Heteronormatividades: formas de violência simbólica e factual com base na orientação sexual e identidade de género}

Autor(es): $\quad$ Santos, Ana Cristina

Publicado por: $\begin{aligned} & \text { Instituto de História Económica e Social; Imprensa da Universidade de } \\ & \text { Coimbra }\end{aligned}$

URL

persistente:

URI:http://hdl.handle.net/10316.2/44503

DOI: $\quad$ DOI:https://doi.org/10.14195/0870-4147_37_11

Accessed : $\quad$ 26-Apr-2023 14:06:59

A navegação consulta e descarregamento dos títulos inseridos nas Bibliotecas Digitais UC Digitalis, UC Pombalina e UC Impactum, pressupõem a aceitação plena e sem reservas dos Termos e Condições de Uso destas Bibliotecas Digitais, disponíveis em https://digitalis.uc.pt/pt-pt/termos.

Conforme exposto nos referidos Termos e Condições de Uso, o descarregamento de títulos de acesso restrito requer uma licença válida de autorização devendo o utilizador aceder ao(s) documento(s) a partir de um endereço de IP da instituição detentora da supramencionada licença.

Ao utilizador é apenas permitido o descarregamento para uso pessoal, pelo que o emprego do(s) título(s) descarregado(s) para outro fim, designadamente comercial, carece de autorização do respetivo autor ou editor da obra.

Na medida em que todas as obras da UC Digitalis se encontram protegidas pelo Código do Direito de Autor e Direitos Conexos e demais legislação aplicável, toda a cópia, parcial ou total, deste documento, nos casos em que é legalmente admitida, deverá conter ou fazer-se acompanhar por este aviso. 


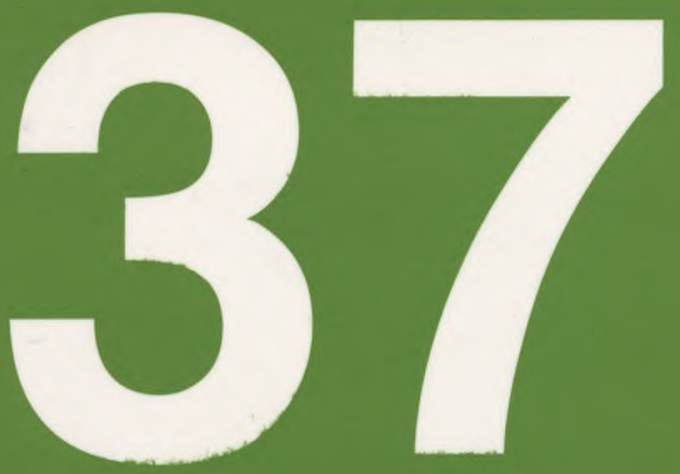

Revista Portuguesa de História

Faculdade de Letras da Universidade de Coimbra Instituto de Historia Econónica e Samial

Coimbra 05 


\section{Heteronormatividades: formas de violência simbólica e factual com base na orientação sexual e identidade de género}

ana Cristina Santos*

CES

\section{Introdução}

Práticas de violência, simbólica ou factual, por motivos que se relacionam com a orientação sexual ou identidade de género são uma constante em Portugal. Estão presentes na ausência de modelos positivos de diversidade sexual nos manuais escolares, na publicidade para o Dia de S. Valentim ou no discurso de responsáveis políticos. Determinam despedimentos e cortes na progressão de carreira, facto que tem recentemente alertado a Intersindical CGTP para a necessidade de constituir um núcleo de trabalho lésbico, gay, bissexual e

* Socióloga. Investigadora do Centro de Estudos Sociais da Universidade de Coimbra e doutoranda em Estudos de Género pela Universidade de Leeds, Reino Unido.

Autora do livro A Lei do Desejo: Direitos Humanos e Minorias Sexuais em Portugal (2005, Porto: Afrontamento). Publicações recentes incluem "Sexual orientation in Portugal: towards émancipation" (South European Society and Politics, Vol. 9, N. 2, Londres: Frank Cass, 159-190; também publicado em português no livro Reconhecer para Libertar, Boaventura de Sousa Santos, org., 2004, Porto: Afrontamento) e "Sexualidades politizadas: o activismo nas áreas da sida e da homossexualidade em Portugal" (Cadernos de Saúde Pública, vol. 18, n 3, Mai-Jun 2002, Ministério da Saúde, Brasil). Vice-Presidente e membro fundador da associação não te prives - Grupo de Defesa dos Direitos Sexuais. 
transgénero (doravante LGBT), à semelhança de outras estruturas sindicais em países europeus. ${ }^{1} \mathrm{E}$ assume formas violentas. Através da comunicação social e do trabalho de denúncia de associações, são hoje conhecidos os ataques à porta da discoteca lisboeta Kings and Queens em 1997, os grupos organizados que ameaçavam gays em Guimarães em 2002, o casal gay que se beijava num parque de Lisboa e foi insultado por polícias, do casal lésbico a quem a Câmara Municipal de Lisboa alegadamente recusou integrar num programa de realojamento em 2004 e da mulher transsexual assassinada no Porto em 2006, entre outros. São muitos os exemplos.

Se considerarmos que o tratamento discriminatório configura uma forma de violência, no que respeita à justiça portuguesa, Portugal conhece também casos de violência simbólica com base na orientação sexual. Basta para o efeito lembrar o caso de João Mouta ${ }^{12}$, um pai gay lutando pela custódia da sua filha menor, cujo texto do acórdão do colectivo de juízes do Tribunal da Relação de Lisboa, presidido pelo juiz Dinis Nunes, em 1996 afirmava que "a menor deve viver no seio de uma família tradicional portuguesa, e esta não é, certamente, aquela que seu pai decidiu constituir, uma vez que vive com outro homem como se de marido e mulher se tratasse". Posteriormente, a 21 de Dezembro de 1999, o Tribunal Europeu dos Direitos Humanos condenou o Estado português pela decisão do Tribunal da Relação de Lisboa. ${ }^{3}$ Mais recentemente, o cronista João César das Neves está a ser processado por repetidamente divulgar ideias que alegadamente violam os direitos constitucionais de gays e lésbicas.

1 Entre outros exemplos, destaco o sindicato britânico UNISON, cujo site do grupo LGBT se encontra em http://www.unison.org.uk/out/index.asp.

2 Pai homossexual em litígio com a ex-mulher pela custódia legal da filha de ambos, viu a sua causa ganha quando, em 1994, o Tribunal de Família, conhecendo a orientação sexual do litigante, lhe concedeu a guarda da filha menor. Tal decisão, inédita na justiça portuguesa, parecia revelar novas possibilidades da aplicação da lei e do direito. Segundo Teresa Coutinho, advogada

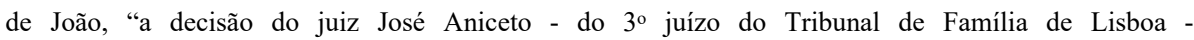
constitui a prova de que a aplicação da lei está a acompanhar os desafios colocados pelos novos modelos familiares, consagrando a possibilidade de os homossexuais homens exercerem o pleno direito à paternidade" (.Expresso, 16/07/94). Porém, após recurso da mãe para o Tribunal da Relação de Lisboa, em 1996, a decisão do Tribunal de Família foi revogada expressamente pela homossexualidade assumida pelo progenitor.

3 Argumentando que essa decisão desrespeita o artigo $14^{\circ}$ da Convenção Europeia dos Direitos Humanos - proibitiva de tratamento discriminatório -, o Tribunal de Estrasburgo condenou Portugal ao pagamento de uma indemnização de 1800 mil escudos ao queixoso, acrescida de 350 mil escudos pelas despesas com o processo. O texto completo do julgamento pode ser consultado em http://www.echr.coe.int/Eng/Judgments.htm, através do número de caso 33290/96. 
Como veremos, estes exemplos não só contrastam com as expectativas que a aproximação à Europa Comunitária criou, como conflituam com as exigências de igualdade de oportunidades e tratamento não discriminatório patentes na Constituição Portuguesa desde 2004.

\section{Enquadramento sociológico da heteronormatividade}

A violência constitui uma prática de poder exercida entre pessoas, instituições ou outras entidades em competição. $O$ enfoque do presente artigo situa-se na fronteira entre a violência de género e a violência sexual, confundindo e articulando os limites de ambas e constituindo, deste modo, uma perigosa forma de violência arremessada contra lésbicas, gays, bissexuais e transgéneros (LGBT) pelos mais diversos motivos. De facto, como sublinham Dworkin e Yi, embora frequentemente ausente dos estudos sobre violência sexual,

Um motivo insidioso subjacente à opressão (...) é a traição das crenças e expectativas de género. As pessoas LGBT frequentemente desafiam noções acerca dos papéis e dicotomias de género. Os homens gays e as mulheres transexuais são vistas como estando a trair a superioridade do seu papel e privilégio masculinos e por essa via devem sofrer punição. As lésbicas e homens transexuais são vistos como estando em busca de um privilégio masculino e, por isso, devem ter um castigo. Em última análise, acredita-se que as pessoas LGBT ameaçam a ordem social estabelecida (Amnistia Internacional, 2001). Esta é uma ideia prevalecente na maior parte do mundo." (Dworkin e Yi, 2003:272)

A violência anti-LGBT alimenta-se de um sistema social baseado na heteronormatividade, que pode ser definida enquanto "um sistema de crença que valoriza a heterossexualidade enquanto superior ou mais natural do que a homossexualidade e/ou parte do pressuposto de que todas as pessoas são inerentemente heterossexuais" (CUISR, 2003). Uma forma de conhecer o grau de heteronormatividade da sociedade portuguesa decorre da análise das respostas em inquéritos à população.

Com base num inquérito realizado em 1998, quase metade dos/as respondentes - 48,5\% - declara que a sexualidade só deveria ser permitida entre homens e mulheres, face a uma percentagem de 14,3\% que advoga deverem ser permitidos todos os tipos de relacionamento sexual (Pais, 1998:411). Quando questionados/as acerca da aceitação das relações sexuais entre dois homens e entre duas mulheres, a incidência de rejeição ascende aos cerca de $80 \%$, sendo, no entanto, de salientar o mesmo grau de não aceitação face ao adultério, mais especificamente 
em relação ao homem casado que mantém relações sexuais com outras mulheres (Pais, 1998: 440).

Estudos mais recentes apontam neste mesmo sentido: numa escala de oscila entre o nunca justificável $(=1)$ e o sempre justificável $(=10)$, a homossexualidade obtém em Portugal 3.19, em contraste com a média da UE que é de 5.36 (Vala et al, 2003: 100).

Mais recentemente, em Junho de 2005, foram divulgados os resultados de um inquérito realizado pela firma de consultadoria Euro RSCG em 10 países europeus, nomeadamente República Checa, Finlândia, França, Alemanha, Itália, Holanda, Polónia, Portugal, Espanha e Reino Unido. Quando questionados acerca da homossexualidade, apenas $51 \%$ dos portugueses respondentes aceitam essa orientação sexual para uma média europeia de 64\%. Entre todos os Estados participantes, somente a Polónia apresentou uma posição mais conservadora. Analisando as respostas com maior detalhe, verifica-se uma acentuada diferença geracional em Portugal: $75 \%$ das pessoas com idades compreendidas entre os 18 e os 24 aceita a homossexualidade, sendo esta percentagem de $25 \%$ entre pessoas com mais de 65 anos. Outras variáveis interessantes são o nível educacional e o local de residência: o grau de aceitação aumenta com o nível de educação e a Região de Lisboa e Vale do Tejo apresenta um índice de aceitabilidade superior à média do país $(61 \%$ face a $45 \%){ }^{4}$

De facto, a homossexualidade e a bissexualidade continuam a revelar-se áreas problemáticas para a maioria da população portuguesa, utilizadas muitas vezes como forma de agressão verbal ou de inferiorização do outro (Almeida, 1995). Esta rejeição da não-heterossexualidade já se revelou de forma violenta num passado recente, configurando situações cujos contornos se enquadram no conceito de violação dos direitos humanos.

Num quadro social heteronormativo, a rejeição de outras orientações sexuais é descrita pelo conceito de homofobia, ou seja, o medo e/ou aversão face à homossexualidade que se traduz em actos de violência simbólica ou factual. A homofobia é um comportamento idêntico ao racismo, à misoginia ou à xenofobia, tratando-se, no fundo, do ódio à diferença que atribuímos ao outro. ${ }^{5}$ Uma maior precisão conceptual obriga-nos a referir ainda a lesbofobia, a bifobia e a transfobia, para descrever tais sentimentos de medo e/ou aversão a lésbicas, bissexuais e transgéneros, respectivamente.

4 Dados disponíveis no Público online, de 5 de Junho de 2005.

5 Por outras palavras, a homofobia descreve um sentimento de rejeição violenta relativamente às "relações afectivas e sexuais entre pessoas do mesmo sexo, um ódio generalizado aos homossexuais e todos os aspectos do preconceito e discriminação antí-homossexual" (http://homofobia.com.sapo.pt/ conceitos.html). 
Num contexto de ausência de campanhas oficiais contra a discriminação por homofobia, em que os manuais escolares enjeitam a diferença sexual, em que a lei é agente passivo e activo de discriminação e onde escasseiam fontes de referência cultural e de modelos positivos que extravasem a heterossexualidade, a heteronormatividade - ou seja, a vigência da heterossexualidade representada enquanto modelo único e/ou superior - acaba por se alimentar a si própria. É este sistema auto-fágico da discriminação com base na orientação sexual e na identidade de género que gera formas de violência que serão objecto de análise nas próximas secções.

\section{Para um perfil da violência sobre minorias sexuais em Portugal}

A violência com base na orientação sexual e na identidade de género é um fenómeno antigo, duradouro e silenciado. Não obstante o baixo número de denúncias - facto explicável pelo medo de outros inconvenientes associados à queixa, como sejam represálias, denúncia pública da orientação sexual da vítima, reacção policial hostil, etc. -, existe uma elevada probabilidade de pessoas LGBT passarem por formas de violência anti-LGBT desde a sua adolescência (D’Augelli, 1998; DiPlacido, 1998). Vejamos o que se passa em Portugal.

\subsection{Casos práticos de violência física}

O primeiro ataque conhecido deu-se em 1996 à porta da discoteca lisboeta Kings and Queens, onde após provocações por parte de um grupo de indivíduos que circulava na zona, dois homossexuais acabaram por ser esfaqueados (cf. Trivia, Outubro/Novembro de 1996). Fora de Lisboa, registaram-se casos de agressão física em Braga e em Évora, ${ }^{6}$ onde grupos de indivíduos se dedicavam a perseguir e a espancar homossexuais masculinos. No final de Maio 2002, a Polícia Judiciária do Porto prendeu um trio de assaltantes que raptava e roubava homossexuais na cidade de Guimarães (24 Horas, 28/05/2002:4). Em Agosto de 2003, duas mulheres foram encaminhadas à esquadra da Polícia de Segurança Pública de Cascais, em sequência de um acidente rodoviário. $\mathrm{Na}$ esquadra, estas duas mulheres, lésbicas, foram alegadamente maltratadas e insultadas em função da sua orientação sexual. Este incidente consta do Relatório da

O primeiro destes casos (Braga) foi largamente noticiado pela comunicação social, o segundo não o chegou a ser, dado que os agredidos não chegaram a apresentar queixa do sucedido por medo de retaliações e de conhecimento público da sua homossexualidade, conforme relatou Sérgio Vitorino, coordenador do Grupo de Trabalho Homossexual (Santos e Fontes, 1999). 
Amnistia Internacional referente ao ano de 2003, colocando Portugal na lista de países onde os direitos LGBT não são respeitados.

Em 2004, vários homens gays da cidade de Viseu foram perseguidos, espancados e ameaçados de morte por um gang organizado para o efeito. Estes casos de violência aconteceram meses depois de, em Outubro de 2004, Femando Ruas, presidente da Câmara de Viseu, ter vindo a público com a intenção de tomar medidas contra alegados actos de prostituição homossexual em áreas de descanso do IP5. Sendo que em Portugal nem a prostituição, nem a homossexualidade constituem crime, estas declarações revelaram um excesso de zelo preocupante, porque desigual - não se conhecem medidas similares destinadas a impedir zonas de prostituição feminina heterossexual. Tudo isto acaba por suscitar mal-estar, remetendo para a patologização de uma identidade sexual tão saudável quanto a heterossexual, como, de resto, insiste em lembrar a Organização Mundial de Saúde.

Ainda em 2004, a Associação Panteras Rosa prestou apoio jurídico a um homem gay, alegadamente vítima de abuso de poder por parte de autoridades, levando à abertura de um inquérito interno na GNR de Coina, facto inédito até então. Já em 2005, recorde-se o caso de Portalegre, em que um sexagenário foi agredido por ser homossexual. Após denúncia nos media, apresentação de queixa e com o apoio de associações de defesa dos direitos sexuais, o desfecho deste caso, em Outubro de 2005, traduziu-se numa decisão judicial em favor da vítima e condenação do agressor a uma pena suspensa e pagamento total das custas judiciais.

Muito recentemente, o país conheceu um crime cujos contornos, ainda em investigação no momento em que este artigo é redigido, parecem estar inegavelmente associados a um crime de ódio por transfobia. A este propósito, relatava o Jornal de Notícias a 23 de Fevereiro de 2006:

Um grupo de doze adolescentes, com idades entre os 10 e os 16 anos, é suspeito de ter espancado até à morte um homem, aparentando 35 anos, travesti, sem-abrigo e toxicodependente. Os menores terão posteriormente lançado o cadáver para um fosso com cerca de dez metros de profundidade no piso subterrâneo de um parque de estacionamento na Avenida Fernão Magalhães (Porto). (...) Com o corpo a boiar de bruços, com as calças desapertadas e baixadas. De acordo com o mergulhador, a vítima tinha escoriações nas nádegas. Os sinais de decomposição do cadáver indiciavam que o homem teria morrido há dois ou três dias.

Repare-se, a este propósito, como a própria identidade sexual da vítima lhe é negada, num primeiro momento, pelos órgãos de comunicação social, que insistiram em tratar Gisberta, imigrante brasileira e mulher transexual, pelo nome masculino, atribuindo-lhe en passant a qualidade de travesti. Na verdade, foram as 
associações de defesa dos direitos LGBT que denunciaram mais esta forma de violência, num comunicado que circulou mundo, descrevendo o crime em detalhe:

"A vítima mortal encontrava-se num estado de saúde profundamente debilitado, e era frequentemente perseguida pelos rapazes, vitima de insultos e agressões. A19 de Fevereiro, um grupo destes rapazes penetrou no edifício inacabado e abandonado onde Gisberta pernoitava, amarrou-a, amordaçou-a e agrediu-a com extrema violência, a pontapé, com paus e pedras. $O$ grupo confessou igualmente ter introduzido paus no anús de Gisberta, que apresentava grandes escoriações nessa zona do corpo, e tê-la abandonado no local. $O$ corpo apresentava igualmente marcas de queimadura com cigarros.

A 20 e 21 de Fevereiro, voltaram ao local e repetiram as agressões. Na madrugada de 21 para 22 de Fevereiro, atiraram finalmente o corpo de Gisberta para o fosso, numa tentativa de ocultação do crime. A autópsia esclarecerá se então a vítima se encontrava ou não viva. $O$ facto de o corpo não se encontrar a flutuar, mas sim submerso no fundo do poço parece indicar que esta faleceu por afogamento nesse momento". (http://tgeu.net/Gisberta/ Languages/GisbertaP.htm)

Este crime, chocante pelo grau de violência e pelo seu carácter visivelmente sexual, ficou também marcado pelo silêncio oficial acerca da transfobia subjacente a todo o processo, comprovando, mais uma vez, que a heteronormatividade exerce o seu poder de forma violenta, simbólica e não simbólica, e cruzando as esferas da sexualidade e do género.

\subsection{Casos práticos de violência simbólica}

Ainda que os casos conhecidos de violência extrema sobre minorias sexuais sejam porventura menos frequentes em Portugal quando comparados a outros países ${ }^{7}$, sabemos que o preconceito e a discriminação assumem muitos rostos, cujas consequências podem ter um idêntico grau de potencial destrutivo da dignidade humana. Seguem-se alguns exemplos.

Em Junho de 1997, pouco tempo após a inauguração do Centro Comunitário Gay e Lésbico de Lisboa, foram colados cartazes em diversos locais desta cidade, onde se lia "Homossexual: a tua doença tem cura... Anima-te!", apelando-se ainda à criação de clínicas para internamento e reabilitação dos homossexuais.

7 No Brasil, por exemplo, a cada 2 dias alguém é assassinado por motivos relacionados com a sua orientação sexual ou identidade de género. De acordo com o relatório Causa Mortis: Homofobia, de Luiz Mott, o Brasil regista um total de 1960 mortes nos últimos 20 anos. Este mesmo estudo identifica 130 homossexuais mortos no Brasil em 2000, dos quais 69\% eram gays, $29 \%$ travestis e $2 \%$ lésbicas. Mais informações disponíveis em www.ggb.org.br. 
Dois anos depois, a 6 de Janeiro de 1999, o Conselho Superior de Estatística fez publicar, na II série do Diário da República, a Classificação Nacional de Deficiências. Neste documento, constava a expressão "deficiência da função heterossexual", fazendo equivaler o homossexual a uma pessoa deficiente por via da sua orientação sexual. Sob o mesmo capítulo das "Deficiências das funções emotiva e volitiva" e subcapítulo das "Deficiências das pulsões", a "deficiência da função heterossexual" está em pé de igualdade com a anorexia, a bulimia, o alcoolismo e a toxicodependência (cf. Diário da República, 06/01/1999, II série, 110). Sob pressão das associações e denúncia nos media, esta classificação acabou por ser revogada.

Ainda em 1999, em declarações divulgadas pelo Diário de Notícias a 17 de Abril, o Presidente do Instituto Português do Sangue defendeu a exclusão de dadores homossexuais masculinos por serem alegadamente muito promíscuos. Após inúmeros casos de dadores rejeitados com base na sua homossexualidade, ${ }^{8}$ esta situação - embora inconstitucional à luz do artigo $13^{\circ}$ - conheceu desenvolvimentos recentes desenvolvimentos. Em Outubro de 2005, o Ministério da Saúde respondeu por escrito à deputada Heloísa Apolónia (Partido Os Verdes), garantindo:

“o Instituto Português do Sangue divulgará um novo texto científico-técnico actualizado através de Circular Normativa Nacional para todos os serviços de saúde com colheita de sangue a dadores, chamando a atenção e condenando práticas já não admitidas, onde elas possam eventualmente existir, com a recomendação de não mais se suspender qualquer dador, sem avaliação clínica, só porque o mesmo referiu a sua orientação sexual”.

Os resultados efectivos deste mesmo documento, assinado pela Chefe de Gabinete, Teresa Oleiro, carecem ainda de confirmação no terreno.

Em 2004, Luís Villas-Boas, Presidente da Comissão de Acompanhamento da Lei da Adopção, reagindo à decisão espanhola de permitir a adopção por homossexuais, afirmou publicamente que seria melhor uma criança passar toda a vida numa instituição ou em famílias de acolhimento à "infelicidade de ser educado por homossexuais, sejam dois ou um" (Público, 18/02/2004).

Um outro caso que, de acordo com as associações de defesa das minorias sexuais, configura o conceito de violência simbólica tem sido protagonizado por João César das Neves através das suas crónicas no Diário de Notícias.

* Note-se que ao potencial dador é entregue um documento que deve ser preenchido e assinado sob honra de serem verdadeiras as afirmações prestadas. Uma destas afirmações consiste em confirmar que o próprio, se for homem, nunca teve relações sexuais com outro homem. 
Alguns dos conteúdos expressos por este autor, associam homossexualidade a fenómenos de pedofilia e doença. ${ }^{9}$ Em Dezembro de 2003, deu entrada uma queixa-crime por "difamação com publicidade", considerada atentatória do direito ao bom-nome de pessoas homossexuais. Este caso está em processo de julgamento, com sessão inicial prevista para Março de 2006.

No início de Novembro de 2005 foi divulgada a notícia de um namoro numa escola secundária portuguesa entre duas alunas 17 e 19 anos. Não obstante o apoio de colegas e da Associação de Estudantes, por uma razão de violência simbólica com base na orientação sexual destas duas mulheres, o namoro foi perseguido pelas auxiliares de educação da escola, que insultaram o casal e apresentaram queixa ao Conselho Executivo. Através de uma denúncia das alunas, foi tomado público o comportamento da Vice-Presidente deste mesmo Conselho Executivo que terá repreendido as estudantes de forma violenta, gritando-lhes "se querem ser lésbicas, sê-lo-ão fora desta escola". Esta escalada culminou com declarações polémicas por parte de um professor das alunas, bem como a denúncia não autorizada da orientação sexual das jovens às suas famílias. A falta de proporcionalidade das medidas tomadas pelo Conselho Executivo desta escola aparece evidente quando se constata que a homossexualidade foi retirada da lista de doenças da Organização Mundial de Saúde e da Associação Norte-Americana de Psiquiatria há mais de uma década.

Este exemplo revela a importância de campanhas de sensibilização e informação em meio escolar, à semelhança do que sucede em algumas escolas britânicas através da Campanha "Education for All", da organização Stonewall. ${ }^{10}$ Todavia, organizações como a Amnistia Internacional identificam as escolas como sendo um dos locais mais perigosos para a juventude LGBT (Amnistia Internacional, 2001). Nos EUA, por exemplo, não só se registam casos de perseguição de estudantes LGBT em meio escolar, como também se verificam frequentes casos de expulsão escolar por este motivo (Dworkin e Yi, 2003: 270).

A terminar esta secção sobre violência simbólica, importa referir dois fenómenos que, quando associados de forma repetida à homossexualidade, constituem armadilhas conceptuais frequentemente transmitidas pelo discurso dos media e posteriormente apropriadas pela opinião pública. Refiro-me à sida e à pedofilia.

9 Ver, entre outros exemplos, as crónicas "Para lá do bem e do mal" (10/02/2003),

“Tragicomédia", (07/04/2003), "Tolerâncias" (12/05/2003) e "Doenças" (14/07/2003).

${ }^{10}$ Informação detalhada acerca da campanha "Education for All" encontra-se disponível em http://www.stonewall.org.uk/education_for_all/default.asp. 
Apesar de em Portugal a população homossexual ser menos afectada pela epidemia do VIH/SIDA do que a população heterossexual, ${ }^{11}$ o estigma social associado à doença continua a pautar-se por um discurso sobre imoralidade, promiscuidade e castigo, frequentemente formulado em jeito de ataque à comunidade LGBT. Por exemplo, os resultados de um inquérito efectuado pelo Instituto dePsicologiaAplicadaem2001 sobre uma amostra de 1000 estudantes portugueses com idades compreendidas entre os 16 e os 23 anos, revelam que a SIDA é vista como uma doença que afecta sobretudo toxicodependentes, prostitutas e homossexuais (.Público, 20/11/2001). Já anteriormente, em 1993, um estudo realizado por Lucas sobre conhecimentos, crenças e atitudes dos portugueses face à SIDA revelava que, relativamente aos grupos considerados mais vulneráveis, $60 \%$ dos inquiridos respondia "homossexuais" (Lucas, 1993:66). Esta associação comprovadamente infundada entre SIDA e determinados grupos sociais é um dos factores responsáveis pela fraca percentagem de testes de SIDA efectuados em Portugal. $\mathrm{Na}$ verdade, informações disponibilizadas pelo Observatório dos Comportamentos e Atitudes em Relação ao HIV/SIDA indicam que em 1998, por exemplo, mais de $70 \%$ dos estudantes do ensino superior nunca havia feito o teste (Público, 20/03/2000). Isto toma-se sobretudo preocupante quando, de acordo com dados da Comissão Nacional de Luta Contra a SIDA divulgados em 1999, $50 \%$ dos seropositivos portugueses foram infectados antes dos 25 anos (idem).

A segunda armadilha conceptual é aquela que associa a homossexualidade masculina a comportamentos pedófilos, aspecto que se tomou particularmente visível em consequência do designado escândalo da Casa Pia. Em finais de 2002, vinha a público um caso de abuso sexual de menores, alunos do Colégio de Pina Manique da Casa Pia de Lisboa, envolvendo figuras públicas nacionais. Num período que mediou entre Novembro e Dezembro de 2002 sucederam-se notícias e testemunhos nos quais se referia sistematicamente a orientação sexual do abusador, fazendo-se muitas vezes coincidir as categorias "pedófilo" e "homossexual". É disso exemplo a utilização de expressões como "práticas homossexuais pedófilas" ou "violações homossexuais" quando as crianças envolvidas eram do sexo masculino. ${ }^{11} 12$ Por seu turno, quando se tratava de

11 Se considerarmos os casos notificados por categoria de transmissão até Junho de 2001, verificamos que os toxicodependentes continuam a ser o grupo mais afectado (49,7\%), seguindo-se os heterossexuais $(27,4 \%)$ e os homo ou bissexuais (16,1\%) (CNLCS, 2001). Os dados mais recentes, reportando-se ao Io trimestre de 2005, revelam que, para os 321 casos de infecção VIH e Sida diagnosticados, a distribuição de acordo com as principais categorias de transmissão e o estádio é a seguinte: 187 heterossexuais, 95 toxicodependentes e 26 homo/bissexuais.

12 A este propósito, por exemplo, a crónica “Associações de Malfeitores”, de João César das Neves, ao Diário de Notícias, 9 Dezembro 2002. 
meninas abusadas por homens, fazia-se uma referência estrita a "abuso sexual", omitindo-se, porventura de forma estratégica ou ingénua - mas seguramente heteronormativa - a orientação sexual do abusador.

\subsection{Impactos da violência sobre minorias sexuais}

Episódios de violência factual e simbólica despertam a vontade colectiva de agir politicamente. Casos flagrantes de injustiça ou violência provocam tradicionalmente um acréscimo da mobilização individual em prol de uma causa; a indignação, afinal, é a semente da acção colectiva. Portanto, em termos de activismo, factos como os que sucederam em Viseu ou Gaia instigam a medidas conjuntas.

O movimento LGBT português tem pouco mais de uma década de existência. Caracteriza-se em traços gerais por ser muito urbanizado, com poucas organizações, mais orientado para medidas políticas do que para acção directa, revelando um elevado poder de ajustamento às novas necessidades e um crescimento significativo no seu reportório cultural e simbólico. Num país onde tudo parece estar ainda por construir em termos de cidadania sexual, o movimento tem dado passos importantes, como são exemplo a aprovação da lei de uniões de facto em Março de 2001, a inclusão de "orientação sexual" entre as razões de proibição da discriminação no artigo $13^{\circ}$ da Constituição em 2004 ou o recente acórdão do Supremo Tribunal de Justiça declarando inconstitucional a manutenção do artigo $175^{\circ}$ do Código Penal. Mas tais avanços são insuficientes, quando contrastados com os bloqueios político-sociais à igualdade.

Uma medida política que vem sendo exigida pelo movimento LGBT em anos recentes é a criação de uma lei anti-homofobia, tal como existe já em diversos países. Tal lei criminalizaria o incitamento ao ódio e qualquer forma de violência com base na orientação sexual ou identidade de género. ${ }^{13} \mathrm{Na}$ mesma linha de argumentação, este movimento colectivo organizou uma petição, entregue na Assembleia da República, no sentido do reconhecimento oficial do 17 de Maio enquanto Dia de Luta Contra a Homofobia.

Não obstante este potencial catalizador, ao nível individual dos sujeitos envolvidos o impacto de formas de violência física ou simbólica é extremamente nefasto. Medo, vergonha, clandestinidade - todos estes elementos acabam por contribuir para a manutenção do chamado "armário", ou seja, a ocultação dos

\footnotetext{
13 Na verdade, para ser exacta tal lei deveria conter expressões específicas face aos diferentes tipos de discriminação que afectam, diferentemente, lésbicas, gays, bissexuais e transgéneros. Por esta razão, é tendencialmente aceite a necessidade de colocar, em paralelo, as discriminações por lesbofobia, homofobia, bifobia e transfobia.
} 
afectos não-heteronormativos e a subjugação identitária ao que os sujeitos interpretam como sendo a norma. Por outras palavras, a violência constitui um poderoso instrumento de acção e manutenção da heteronormatividade.

A repressão que é exercida, de forma directa ou tácita, sobre as minorias sexuais traduz-se frequentemente em sentimentos de depressão, culpa e elevadas taxas de mortalidade. ${ }^{14} \mathrm{Na}$ verdade, o preconceito por homofobia, lesbofobia, bifobia e/ou transfobia é responsável pelo abuso de substâncias prejudiciais e tentativas de suicídio, com elevada incidência particularmente entre adolescentes e jovens não heterossexuais. De acordo com um estudo realizado em 2003 no Canadá, registam-se anualmente entre 818 e 968 mortes por suicídio relacionado com orientação sexual ou identidade de género, sendo que estes factores respondem por 30\% dos suicídios registados naquele país (CUISR, 2003).

A violência sexual exerce-se não raramente sob a forma de ameaças e perseguições, quer por parte de familiares, quer por parte de colegas. Às associações LGBT chegam vários pedidos de ajuda de jovens expulsos de casa ou de adultos/as sem emprego por via da sua sexualidade. Estas e outras formas de represália vitimaram, de resto, Teresa e Helena - conhecidas por terem protagonizado a primeira tentativa de casamento civil entre pessoas do mesmo sexo em Portugal, a 1 de Fevereiro de 2006 -, e que, estando ambas desempregadas foram ainda vítimas de injúrias e ameaças por parte de seus vizinhos. ${ }^{15}$ Quando confrontados por jornalistas, os vizinhos justificaram-se, dizendo que:

“O que se passa é que elas fazem muito barulho durante a noite e há quem não consiga dormir”. Sobre o tipo de mido, os relatos dividem-se. Uns falam de "música", outros de transportes amorosos: "Aquilo parece o canal Playboy । Há até quem assuma nunca ter ouvido nada de especial, mas estar solidário com os que ouvem. "Elas já foram avisadas antes, até já as ameaçámos com a polícia...". Ao longo da conversa, porém, alguns concretizam outros agravos: "Elas são muito escandalosas, não se privam de nada. Sempre de mão dada, aos beijos...". Há até quem lance suspeitas: "Recebem muitos homens... Houve quem visse o número de telefone delas num jornal da região, a anunciar um show lésbico". Qual jornal não se concretiza.

14 Para um estudo sobre a relação entre orientação sexual e identidade de género e depressão, por um lado, e depressão e desemprego, por outro, ver por exemplo CUISR, 2003: 32-34.

15 De acordo com a descrição das próprias, "Estávamos em casa a fazer o jantar, bateram-nos à porta e estava toda a gente do prédio no patamar, com crianças e tudo. Começaram a acusar-nos de fazermos muito barulho durante a noite, puseram em causa a nossa capacidade de termos uma criança connosco, disseram que tinha sido uma vergonha aparecermos na televisão... E chegaram a ameaçar bater-nos" (Diário de Notícias, 23/02/2006). 
Mas a "má fama" que as duas teriam deixado "noutros sítios onde viveram" é garantida por fonte segura: "Leia o artigo de um padre num jornal da região". (Diário de Notícias, 23/02/2006).

Os contornos discriminatórios de tais afirmações e silêncios são demasiadamente evidentes para exigirem uma análise detalhada. De todo o modo, parecem configurar um tipo-ideal de perseguição kafkiana por motivos de orientação sexual.

Um outro impacto da violência exercida em contexto de heteronormatividade revela-se no adiamento sucessivo de direitos fundamentais. Disso trata a próxima secção.

\section{Contextos institucionais em mudança}

Diversas instituições internacionais têm vindo a incluir Portugal no leque dos países europeus nos quais alterações legislativas tendo por base a orientação sexual e a identidade de género são prementes. Para os propósitos deste artigo, destacam-se algumas iniciativas do Conselho da Europa e da União Europeia a este respeito.

A Assembleia Parlamentar do Conselho da Europa foi pioneira ao considerar os direitos LGBT como direitos humanos através da Recomendação 924/1981, datada de 1981. Entre outras questões, neste documento pedia-se a todos os Estados-membros que revogassem a legislação nacional que criminalizava a homossexualidade e que igualizassem as idades de consentimento para heterossexuais e não-heterossexuais e que garantissem direitos de custódia e visita aos pais e mães lesbigays. Transpondo esta recomendação para o contexto português, vemos que se, por um lado, a homossexualidade foi descriminalizada em 1982 (um ano após a recomendação 924), por outro os direitos de custódia têm sido atropelados ${ }^{16} \mathrm{e}$, em 2006, ainda vigoram diferentes idades de consentimento.

Ainda no âmbito do Conselho da Europa, também a acção do Tribunal Europeu dos Direitos Humanos tem sido marcada pelo empenho na defesa dos direitos LGBT, sendo palco de casos que opõem cidadãos litigantes aos seus próprios países. Foi o que sucedeu em Novembro/Dezembro de 1998, quando este Tribunal aceitou o já referido caso Mouta versus Portugal, tendo decidido favoravelmente à pretensão deste pai gay. ${ }^{17}$

${ }^{16} \mathrm{O}$ caso Mouta versus Portugal, levado ao Tribunal Europeu dos Direitos Humanos, constitui um bom exemplo. Vide supra, Introdução, e infra, nota 17.

17 O texto completo do julgamento pode ser consultado, através do número de caso 33290/96, em http://www.echr.coe.int/Eng/Judgments.htm. 
No que se refere à União Europeia, verifica-se que esta tem apoiado consistentemente os direitos LGBT desde sempre. O primeiro instrumento legal obrigatório da Comissão Europeia referindo-se à orientação sexual foi a Regulação 781/98, uma emenda ao Regulamento do Pessoal da Comissão que insere um novo artigo 1 a determinando que todos os funcionários devem receber igual tratamento independentemente da sua orientação sexual. ${ }^{18}$ Embora sem carácter vinculativo, as recomendações do Parlamento Europeu revestem-se de uma importância crucial, constituindo instrumentos de protecção ffequentemente eficazes, embora retóricos. Assim, importa recordar que, a 4 de Setembro de 2003, o Parlamento Europeu aprovou em sessão plenária uma resolução na qual:

"Solicita uma vez mais aos Estados-Membros a abolição de qualquer forma de discriminação - legal ou de facto - de que ainda são vítimas os homossexuais, nomeadamente em matéria de direito ao casamento e à adopção de crianças', [... ] Exorta Portugal, a Irlanda e a Grécia a alterarem rapidamente as respectivas legislações que prevêem uma diferença das idades de consentimento em função da orientação sexual, dado o carácter discriminatório destas disposições". ${ }^{19}$

Muito recentemente, a 18 de Janeiro de 2006, tomou-se conhecida uma recomendação do Parlamento Europeu que convidou os Estados-Membros a garantir que "as pessoas lésbicas, gays, bissexuais e transsexuais sejam protegidas dos discursos de ódio e das violências homófobas e a agir para que os parceiros do mesmo sexo gozem do mesmo respeito, da mesma dignidade e da mesma protecção que o resto da sociedade". ${ }^{20} \mathrm{O}$ mesmo documento refere a preocupação do Parlamento Europeu em combater a homofobia, nomeadamente através da educação e do reconhecimento do facto de o Holocausto nazi ter assassinado intencionalmente gays e lésbicas.

Não obstante a importância institucional de recomendações europeias, é no plano nacional que se jogam as medidas de maior impacto directo sobre os sujeitos. É por esta razão que importa assinalar que, em 2006, existem ainda em Portugal diferentes idades de consentimento para relações sexuais

18 Por outras palavras, de entre os funcionários da Comissão, ninguém pode ser despedido por ser lésbica, gay, bissexual ou transgénero.

19 Ênfase minha. O texto integral desta resolução encontra-se disponível em http://www.europarl. eu.int/home/default_pt.htm. Acedida a 18/4/2003.

20 Todo o documento disponível em http://www.europarl.eu.int/news/expert/infopress_page/ 016-4330-17-1 -3-902-20060113IPR04270-17-01 -2006-2006-false/default_pt.htm. 
heterossexuais, cuja idade mínima de consentimento é 14 anos, e relações sexuais homossexuais, cuja idade mínima é 16 anos. ${ }^{21}$ Este diferencial etário contraria diversas recomendações europeias, como vimos anteriormente. Outras exclusões jurídicas reportam-se ao direito de casar e constituir família, ao direito de adopção e ao acesso à procriação medicamente assistida para mulheres lésbicas.

Mas também no plano nacional se registam alterações com impacto positivo - pelo menos simbólico - na desconstrução da heteronormatividade. Porventura a mudança mais significativa a este respeito aconteceu a 22 de Abril de 2004, quando a Assembleia da República procedeu a uma revisão constitucional aprovada por maioria. Desde esta data, a Constituição Portuguesa, no seu artigo $13^{\circ}$, define o Princípio de Igualdade:

"1. Todos os cidadãos têm a mesma dignidade social e são iguais perante a lei. 2. Ninguém pode ser privilegiado, beneficiado, prejudicado, privado de qualquer direito ou isento de qualquer dever em razão de ascendência, sexo, raça, língua, território de origem, religião, convicções políticas ou ideológicas, instrução, situação económica, condição social ou orientação sexual".

Todavia, as medidas políticas a este nível continuarão a carecer de eficácia enquanto não forem acompanhadas pelo reconhecimento cultural da comunidade LGBT. Espaços de sociabilidade são essenciais, não só na consolidação de uma identidade que se confronta diariamente com a ausência de modelos positivos, mas também para produzir visibilidade social e criar pontes com a sociedade em geral. ${ }^{22}$ Não se trata de guetizar, como por vezes se teme. Trata-se de permitir espaços seguros sem imposições de heteronormatividade que representam muitas vezes que um casal lésbico ou gay não possa estar de mãos dadas num bar da cidade de Coimbra sem ser convidado a sair. Urgem, portanto, espaços em que a diversidade seja valorizada, mais do que meramente tolerada, e em que a segurança decorra do abandono de espaços clandestinos em troca de uma crescente participação no espaço público.

Uma mudança que acompanha as transformações institucionais - ora precedendo-as, ora juntando-se-lhes a juzante - situa-se na já referida militância sexual. Com efeito, socorrendo-se de novas oportunidade no campo jurídico, o movimento

21 Na verdade, o art. 175 do Código Penal, "descaminho de menores por maiores do mesmo sexo", ao repetir interdições presentes noutros artigos - "abuso sexual de crianças" (artigo $172^{\circ}$ ), "abuso sexual de adolescentes e dependentes" (artigo 173) e "estupro" (artigo 174) - parece punir também a orientação sexual do abusador.

22 Para um estudo acerca dos espaços de sociabilidade homossexual em meio urbano, ver Vieira, 2005. 
LGBT tem vindo a utilizar de forma crescente o poder de denúncia e queixa de situações consideradas discriminatórias, potenciando o grau de visibilidade dos temas LGBT a nivel social. ${ }^{23}$

\section{Conclusão}

Como vimos, atitudes de heteronormatividade institucional, aliadas ao crescimento de grupos de extrema-direita organizados, ausência de urna educação sexual livre e informada a nivel escolar, crise económica, falta de campanhas de sensibilização para a valorização da diferença, inexistência de protecção legal efectiva - todos estes factores contribuem para a explosão de focos de violência dirigida contra diversas minorias, incluindo lésbicas, gays, bissexuais e transgéneros.

A mudança social nunca acontece sem rupturas. Daí que historicamente as revoluções marquem momentos de viragem social. Ora, nesta matéria, como noutras directamente ligadas à dignidade do ser humano, não se pode justificar a manutenção da discriminação através de uma alegada ausência de capacidade social ou de vontade política. A situação tomou-se demasiado insustentável para quem, sob os auspícios da cidadania, cumpre inúmeros deveres, vendo os seus direitos quotidianamente coarctados em função da sua orientação sexual ou identidade de género.

Desde 22 de Abril de 2004 houve uma mudança fundamental, que falta fazer respeitar: a Constituição Portuguesa proíbe a discriminação em função da orientação sexual. Por isso, importa cumprir a Constituição. E importa perder a vergonha. O preconceito combate-se com a visibilidade. E neste processo as instituições de produção de saber- o Estado, as escolas, as universidades, as unidades de investigação científica, etc. - têm um papel fundamental a desenvolver.

Numa sociedade ainda sexualmente conservadora, a mensagem política tem vindo a mudar no sentido de promover o respeito pela diversidade sexual. O Estado parece reconhecer gradualmente a importância da informação e da discussão pública de assuntos perante os quais a sociedade portuguesa tradicionalmente se calou, quer na rua, quer em casa. Contudo, até à data tal evolução tem-se caracterizado por uma hesitação legal: verificam-se poucas medidas de combate activo à discriminação. De facto, no campo dos direitos de lésbicas, gays, bissexuais e transgéneros (LGBT), tal ambiguidade toma-se particularmente

23 Noutro lugar analiso os potenciais e os riscos decorrentes desta associação entre o jurídico e o activismo LGBT. Ver Santos, 2005, capítulo 8. 
evidente: se, por um lado, o Estado adopta medidas legais determinantes no combate à discriminação - a aprovação da lei das uniões de facto a 15 de Março 2001 é um exemplo -, por outro lado, na maior parte das situações, a acção estatal pauta-se ora pela omissão legal, ora pela ausência de regulamentação e aplicação efectiva (Santos e Fontes, 2001). Contudo, tais ausências jurídicas facilitam situações desigualdade e exclusão. Até ao momento presente, a lei portuguesa não criminaliza actos de violência simbólica - tais como o incitamento ao ódio - com base na orientação sexual e identidade de género, apesar das reivindicações de associações que trabalham no terreno.

As consequências positivas de uma evolução em termos de sexualidade extravasam os direitos LGBT. De facto, a protecção dos direitos sexuais é uma forma de tomar as sociedades democráticas mais inclusivas para todos e todas, constituindo uma forma de "democratizar a democracia" (Sousa Santos, 1998). Numa sociedade em que a diferença é, em si, um valor patrimonial, é importante combater a hegemonia da heteronormatividade sexual.

\section{Bibliografia}

Amnistia Internacional (2001), Crimes of Hate, Conspiracy of Silence. Oxford: The Alden Press.

CUISR-Community: University Institute for Social Research (2003), The Cost of Homophobia: Literature Review on the Human Impact of Homophobia

On Canada. Saskatoon: Building Healthy Sustainable Communities.

D'AUGELLI, A. R. (1998) - "Developmental implications of victimization of lesbian, gay, and bisexual youth”, G. M. HEREK (org.) - Stigma and Sexual Orientation: Understanding prejudice against lesbians, gay men, and bisexuals. Thousand Oaks, CA: Sage, 187-210.

Di PLÁCIDO, J. (1998) "Minority stress among lesbians, gay men, and bisexuals: A consequence of heterosexism, homophobia, and stigmatization", G. M. HEREK (org.) - Stigma and Sexual Orientation: Understanding prejudice against lesbians, gay men, and bisexuals. Thousand Oaks, CA: Sage, 138-159.

DWORKIN, S. H.; Yi, H. (2003) - "LGBT Identity, Violence, and Social Justice:

The Psychological is Political", International Journal for the Advancement of Counselling, Vol. 25, ${ }^{\circ}$ 4, December 2003, 269-279.

LUCAS, J. S. (1993) - AIDS: A Sexualidade Desprevenida dos Portugueses.

Lisboa: McGrawHill.

MOTT, Luiz - Causa Mortis: Homofobia. www.ggb.org.br.

PAIS, José Machado (org.) (1998)- Gerações e Valores na Sociedade Portuguesa

Contemporânea. Lisboa: Secretaria de Estado da Juventude. 
SANTOS, Ana Cristina; FONTES, Femando (2001) - "O Estado portugués e os desafíos da (homo)sexualidade", Revista Crítica de Ciências Sociais, 59, Fevereiro.

SANTOS, Ana Cristina (2005) - A Lei do Desejo - Direitos Humanos e Minorias Sexuais em Portugal. Porto: Afrontamento.

SOUSA SANTOS, Boaventura de ( 1998) - "Globalização: o Regresso das Identidades", seminário proferido na Faculdade de Economia da Universidade de Coimbra, 18/03/1998.

VALA, Jorge; CABRAL, Manuel Villaverde; RAMOS, Alice (orgs.) (2003) Valores Sociais: Mudanças e Contrastes em Portugal e na Europa. Lisboa: Imprensa de Ciencias Sociais.

VIEIRA, Paulo Jorge (2005) - Aeminiumqueer: cidade e homossexualidades percepção e sociabilidade. Dissertação de licenciatura em Geografia, Faculdade de Letras da Universidade de Coimbra. 